\title{
Source parameters and site amplifications estimated by generalized inversion technique: focusing on the 2018 Hokkaido Iburi-Tobu earthquake
}

\author{
Kenichi Nakano ${ }^{1 *}$ (10) and Hiroshi Kawase ${ }^{2}$
}

\begin{abstract}
The 2018 Hokkaido Iburi-Tobu earthquake occurred on September 6 . In this earthquake, seismic intensity 7 was measured at Shikanuma, Atsuma Town, and severe damage occurred in Hokkaido. The strong motions were recorded at observation stations including those nearby the epicenter, and the seismograms at a few stations close to the epicenter showed pulse-like waveforms. In the region called Yufutsu Plain, the underground structure is quite complex because Yufutsu Plain is located at the western margin of the Hidaka collision zone. Thus, the mechanism of generating the observed high-amplitude ground motions in this area has not been clarified yet. We performed the generalized inversion technique to estimate the fundamental characteristics of source terms and site amplifications at Yufutsu area to investigate the mechanism mentioned above. We found that the stress drop of the mainshock of the 2018 Hokkaido Iburi-Tobu earthquake was approximately 10Mpa, which corresponds to the upper limit of the crustal earthquakes in the past, and that the short-period level $A$ was approximately $1.17 \times 10^{19} \mathrm{~N} \cdot \mathrm{m}$. We also evaluated the site amplification at sites close to the aftershock zone. We found that the sites in the north with relatively high altitudes showed dominant frequencies above several $\mathrm{Hz}$, while the sites in the south with relatively low altitudes showed dominant frequencies of approximately $1 \mathrm{~Hz}$ or lower. We also found that the site amplifications were quite large at three sites (BBC, HKD126 and IBUH03) where we observed clear pulse-like waveforms, and confirmed that they all showed dominant frequencies at approximately $1 \mathrm{~Hz}$.
\end{abstract}

Keywords: 2018 Hokkaido Iburi-Tobu earthquake, Stress drop, Short-period level A, Site amplification

\section{Introduction}

The 2018 Hokkaido Iburi-Tobu earthquake occurred on September 6, which was a crustal earthquake centered directly under a city. In particular, in the 2018 Hokkaido Iburi-Tobu earthquake, the Japan Meteorological Agency's (JMA) seismic intensity 7 was measured for the first time in Hokkaido. The seismic moment of this earthquake was $M_{0}=1.0 \times 10^{19} \mathrm{~N} \cdot \mathrm{m}$ estimated by F-net, and the $M_{\text {IMA }}$ was 6.7 evaluated by JMA.

\footnotetext{
*Correspondence: nakano.kenichi@ad-hzm.co.jp

${ }^{1}$ Technical Research Institute, HAZAMA ANDO CORPORATION, 515-1

Karima, Tsukuba 305-0822, Japan

Full list of author information is available at the end of the article
}

The JMA estimated the earthquake location as follows: The latitude was $42.6908^{\circ}$ north, the longitude was $142.0067^{\circ}$ east, and the depth was $37.4 \mathrm{~km}$. However, this depth was much deeper than those of general crustal earthquakes in Japan. Moreover, this earthquake location is close to the Ishikari-Teichi-Toen fault zone estimated by the Headquarters for Earthquake Research Promotion (HERP).

During the 2018 Hokkaido Iburi-Tobu earthquake, many strong motion records were obtained from areas including those near the epicenter. In southern Hokkaido, the seismicity of subduction zone earthquakes in the off-Tokachi region is high, but that of crustal earthquakes is relatively low in comparison with other regions in Japan. Regarding the factors for generating strong 
motions, current information on the source and the path of a crustal earthquake in southwestern Hokkaido as well as the local site amplification characteristics is insufficient for quantitative strong motion prediction.

The aim of the present study is to delineate the fundamental characteristics of the 2018 Hokkaido Iburi-Tobu earthquake which contribute significantly to reproducing observed strong ground motions. This paper briefly reports on the results of the analysis obtained by using generalized inversion technique (GIT).

\section{Overview of strong motions at near field from the epicenter in the 2018 Hokkaido lburi-Tobu earthquake}

Here, by showing major strong motion records collected for the 2018 Hokkaido Iburi-Tobu earthquake, the important features of this earthquake are overviewed. Figure 1a shows seismic observation points installed by public institutions near the epicenter of the mainshock of the 2018 Hokkaido Iburi-Tobu earthquake. In this figure, the triangles represent the seismic observation points, the asterisk represents the epicenter, and the circles represent the epicenters of the aftershocks between September 6 and 14, 2018 (by JMA). This figure also shows the focal mechanism solution obtained by F-net which indicates that this earthquake was primarily a reverse fault earthquake with a high dip angle. The estimated fault model published by the Geospatial Information Authority of Japan (GSI 2018), the bottom end of which is approximately $30 \mathrm{~km}$ deep, is slightly shallower than the aftershock region based on information from the source provided by JMA.

Figure $1 \mathrm{~b}, \mathrm{c}$ shows the velocity-time history and pseudovelocity response spectra $\mathrm{pSv}(h=5 \%)$ observed at six points near the epicenter, respectively (these are EW component). As shown in Fig. 1b, clear pulse-like waveforms (it means that the waveforms have a couple of pulses with a dominant frequency and a large amplitude) were observed at HKD126, BBC (47004) and IBUH03 near the epicenter. $\mathrm{BBC}$ is an observation point installed by JMA (Shikanuma,

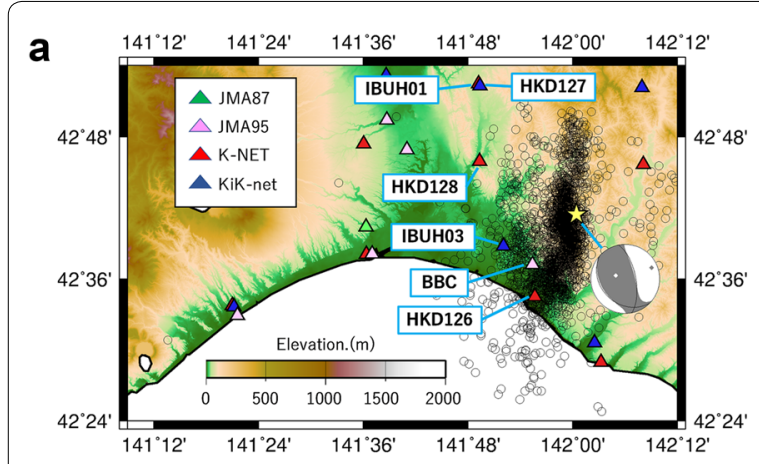

b
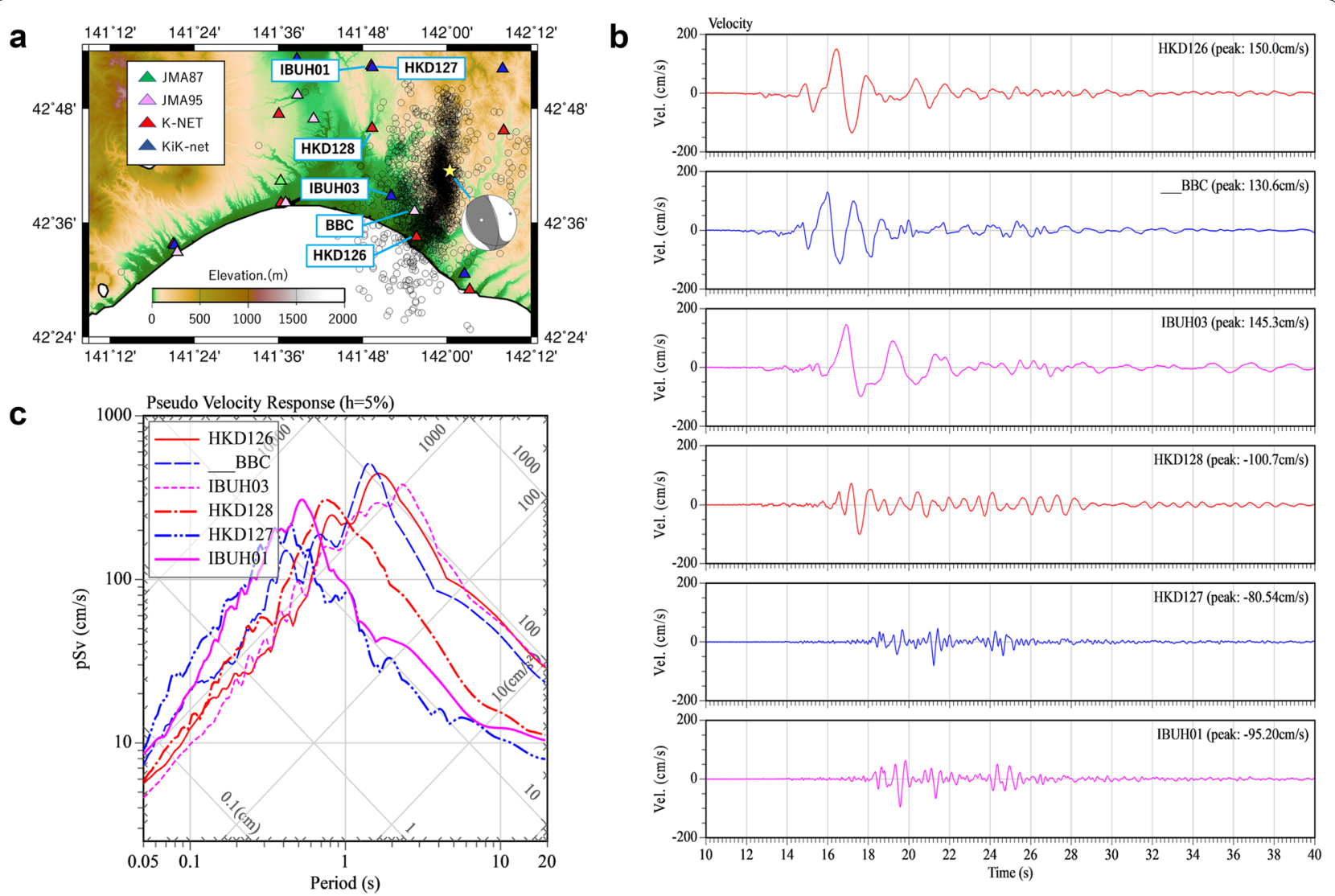

Fig. 1 a Location map of the observation sites with the focal mechanism solution estimated by F-net, and plotting epicenter of aftershocks indicated by circle symbols. b Waveforms are all velocity of EW component. We corrected the arrival time according to JMA travel time table. $\mathbf{c}$ Pseudo-velocity response spectra (pSv) are shown in the figure 
Atsuma Town) where an instrumental seismic intensity of 7 was recorded. At these points, the maximum velocity reached approximately $140 \mathrm{~cm} / \mathrm{s}$.

On the other hand, HKD128 lies at the northwestern side of the epicenter, and the hypocentral distance of HKD128 was slightly larger than those of HKD126, BBC and IBUH03. Therefore, not only the amplitude becomes less (about $100 \mathrm{~cm} / \mathrm{s}$ ) but also the shape of the pulselike waveforms becomes complicated. At HKD127 and IBUH01, which lie at the north-northwest side of the epicenter, the pulse-like waveforms were not clearly observed, and the waveform periods were apparently shorter. If the rupture started from a deeper part of the fault and propagated upward on the fault plane, the waves could grow up to form a pulse-like wave which have a dominant period determined by the size of an asperity, because of the forward rupture directivity. So, the forward directivity effects are thought to have clearly appeared at the sites mentioned above.

According to the damage surveys and investigations published by the National Institute for Land and Infrastructure Management (2018), severe building damage such as collapses was concentrated to dwelling houses combined with stores, which may have a large opening in the front side. Particularly in Shikanuma, Atsuma Town, where the seismic intensity 7 was observed at BBC station, cracks in the ground were created near the JMA's seismic intensity meter, and school buildings located on the extension line of these cracks were severely damaged. It is worth noting that the damage to buildings in areas surrounding the cracks was very low. As mentioned above, there are many unknown points about the relationship between the obtained large-amplitude records and the observed building damage.

\section{Analysis based on spectral inversion technique}

In this study, GIT was performed after adding data obtained during the 2018 Hokkaido Iburi-Tobu earthquake and the 2018 northern Osaka prefecture earthquake to the dataset used by Nakano et al. (2019).

Here, for the Fourier spectrum amplitude in the S-wave section of the seismic waveforms, we used a formularization using S-wave far-field approximation, as shown in Eqs. (1) and (2):

$$
\log F_{i j}=\log S_{i}-n_{l(i)} \log X_{i j}+\sum_{k} b_{l(i) k} X_{i j k}+\log G_{j}
$$

$$
X_{i j}=\sum_{k} X_{i j k}
$$

where $F_{i j}$ is the Fourier spectrum amplitude, $S_{i}$ is the $i$ th source characteristic and $G_{j}$ is the site amplification for ground point $j$. Moreover, $n$ represents the geometric attenuation, which has a value of 1.0 for a body wave and 0.5 for a surface wave theoretically.

In Eq. (1), $b$ is a term that represents a combination of internal and scattering attenuation, and log represents the common logarithm. We showed the analytical conditions below, but for the detailed analytical conditions, please refer to Nakano et al. $(2015,2019)$. We paid attention to the regionality, and the attenuation term $b$ was chosen based on six regions (where $k$ is the index for regions) including Quaternary period volcanoes and the Itoigawa-Shizuoka tectonic line. Earthquakes were differentiated into the following types: Type B (plate-boundary earthquakes), Type I (intraplate earthquakes) and Type $\mathrm{C}$ (crustal earthquakes). The term $l(i)$ represents the type of the $i$ th earthquake. The term $X_{i j}$ multiplied with the attenuation term is the hypocentral distance, with $X_{i j k}$ representing the apparent distance passing through the region $k$. (It is determined by the distribution of horizontal distance passing through a specific region $k$.) We evaluated the all unknown parameters of Eq. (1), based on the dataset including new records mentioned above.

We used accelerograms observed at K-NET and KiK-net, CEORKA, JMA 87-type electromagnetic strong motion seismographs and JMA 95-type seismic intensity meters. The data satisfied the following conditions: hypocentral distance $\leq 200 \mathrm{~km}$, minimum acceleration $\geq 0.2 \mathrm{~cm} / \mathrm{s}^{2}$, peak ground acceleration (PGA) $\leq 200 \mathrm{~cm} / \mathrm{s}^{2}$ and number of stations uniquely identifying an earthquake $\geq 3$. After performing GIT for the S-wave section, site amplification factors with full waves were separately evaluated for the total earthquake duration according to Nakano et al. (2019). We should note that site amplification factors with full waves are relative to the bedrock motion of the incoming S-wave, and so, it is always equal to or higher than the amplification factors with S-waves.

Table 1 lists the information of the mainshocks and the aftershocks in the 2018 northern Osaka prefecture earthquake and the 2018 Hokkaido Iburi-Tobu earthquake, which were added to the datasets of Nakano et al. (2019). For seismic parameters shown in this table, we referred to the JMA's seismological catalogue. However, $M_{0}$ used in this table was that estimated by F-net (Fukuyama et al. 1998). In this table, we showed the corner frequency $f_{\mathrm{c}}$ and cutoff frequency $f_{\max }$ which were simultaneously estimated by performing a grid search so that the residual of source spectra $M_{i}$ and $\omega^{-2}$ model $M_{i}^{(m)}$ became the smallest in a broadband of $0.1-20 \mathrm{~Hz}$. The source spectrum $M_{\mathrm{i}}$ and the $\omega^{-2}$ model $M_{i}^{(m)}$ are expressed by Eqs. (3) and (4).

$$
M_{i}=\frac{4 \pi \rho V_{S}^{3}}{\omega^{2} R_{\theta \varphi} F_{S} P_{R}} S_{i}
$$


Table 1 List of earthquakes and inversion results for source terms

\begin{tabular}{|c|c|c|c|c|c|c|c|c|c|c|}
\hline \multirow[t]{2}{*}{ No. } & \multirow[t]{2}{*}{ Date } & \multicolumn{3}{|c|}{ Hypocenter location } & \multirow[t]{2}{*}{$M_{\text {JMA }}$} & \multirow{2}{*}{$\begin{array}{l}M_{0} \\
(\mathrm{~N} \cdot \mathrm{m})\end{array}$} & \multirow[t]{2}{*}{$f_{c}(\mathrm{~Hz})$} & \multirow[t]{2}{*}{$f_{\max }(\mathrm{Hz})$} & \multirow{2}{*}{$\begin{array}{l}\text { Stress drop } \\
(\mathrm{MPa})\end{array}$} & \multirow{2}{*}{$\begin{array}{l}\text { Short-period level A } \\
\left(\mathrm{N} \cdot \mathrm{m} / \mathrm{s}^{2}\right)\end{array}$} \\
\hline & & Lat. & Lon. & $\begin{array}{l}\text { Depth } \\
(\mathrm{km})\end{array}$ & & & & & & \\
\hline \multicolumn{11}{|c|}{ Mainshock and aftershocks } \\
\hline 1 & 201806180758 & 34.844 & 135.622 & 13 & 6.1 & $2.32 \mathrm{E}+17$ & 0.483 & 15.1 & 4.839 & $2.14 \mathrm{E}+18$ \\
\hline 2 & 201806181631 & 34.859 & 135.611 & 11 & 3.5 & $1.33 \mathrm{E}+14$ & 4.316 & 17.0 & 1.980 & $9.78 \mathrm{E}+16$ \\
\hline 3 & 201806190031 & 34.859 & 135.607 & 10 & 4.1 & $7.80 E+14$ & 2.545 & 13.9 & 2.380 & $1.99 \mathrm{E}+17$ \\
\hline 4 & 201806190453 & 34.844 & 135.626 & 13 & 3.9 & $2.99 E+14$ & 3.724 & 14.7 & 2.859 & $1.64 \mathrm{E}+17$ \\
\hline 5 & 201806190650 & 34.85 & 135.611 & 12 & 3.5 & $1.17 \mathrm{E}+14$ & 4.779 & 14.7 & 2.364 & $1.06 \mathrm{E}+17$ \\
\hline 6 & 201806190752 & 34.846 & 135.613 & 10 & 3.9 & $2.97 \mathrm{E}+14$ & 4.068 & 9.6 & 3.701 & $1.94 \mathrm{E}+17$ \\
\hline 7 & 201806200347 & 34.858 & 135.614 & 11 & 3.4 & $8.30 E+13$ & 4.841 & 17.1 & 1.743 & $7.68 \mathrm{E}+16$ \\
\hline 8 & 201806232308 & 34.832 & 135.622 & 10 & 4.0 & $7.39 E+14$ & 2.545 & 21.7 & 2.255 & $1.89 \mathrm{E}+17$ \\
\hline 9 & 201807011242 & 34.858 & 135.608 & 11 & 3.5 & $8.41 E+13$ & 6.170 & 13.7 & 3.657 & $1.26 \mathrm{E}+17$ \\
\hline 10 & 201807081545 & 34.831 & 135.619 & 10 & 3.9 & $2.90 E+14$ & 3.536 & 16.0 & 2.374 & $1.43 E+17$ \\
\hline 11 & 201809060308 & 42.691 & 142.007 & 37 & 6.7 & $1.00 E+19$ & 0.172 & 18.0 & 9.420 & $1.17 E+19$ \\
\hline 12 & 201809060611 & 42.67 & 142.016 & 37 & 5.4 & $1.54 \mathrm{E}+17$ & 0.529 & 17.0 & 4.220 & $1.70 E+18$ \\
\hline 13 & 201809061439 & 42.783 & 141.978 & 35 & 4.2 & $2.18 \mathrm{E}+15$ & 2.096 & 15.2 & 3.716 & $3.78 \mathrm{E}+17$ \\
\hline 14 & 201809061653 & 42.688 & 141.973 & 34 & 4.4 & $2.76 \mathrm{E}+15$ & 2.085 & 16.2 & 4.631 & $4.74 \mathrm{E}+17$ \\
\hline 15 & 201809062235 & 42.612 & 141.953 & 29 & 4.0 & $7.93 \mathrm{E}+14$ & 3.828 & 10.5 & 8.235 & $4.59 \mathrm{E}+17$ \\
\hline 16 & 201809071325 & 42.701 & 141.971 & 34 & 4.5 & $5.44 \mathrm{E}+15$ & 1.568 & 17.2 & 3.882 & $5.28 \mathrm{E}+17$ \\
\hline 17 & 201809071712 & 42.72 & 141.986 & 34 & 3.5 & $3.82 \mathrm{E}+14$ & 4.314 & 16.4 & 5.678 & $2.81 E+17$ \\
\hline 18 & 201809072243 & 42.746 & 142.022 & 35 & 4.4 & $4.57 \mathrm{E}+15$ & 1.822 & 15.8 & 5.117 & $5.99 E+17$ \\
\hline 19 & 201809080128 & 42.679 & 141.988 & 34 & 4.0 & $9.41 \mathrm{E}+14$ & 2.690 & 17.5 & 3.391 & $2.69 \mathrm{E}+17$ \\
\hline 20 & 201809081821 & 42.696 & 141.969 & 33 & 4.2 & $1.45 E+15$ & 3.281 & 8.6 & 9.481 & $6.16 \mathrm{E}+17$ \\
\hline 21 & 201809092255 & 42.781 & 141.984 & 34 & 4.9 & $2.66 \mathrm{E}+16$ & 0.981 & 18.8 & 4.649 & $1.01 E+18$ \\
\hline 22 & 201809111254 & 42.733 & 141.887 & 13 & 4.3 & $1.90 \mathrm{E}+15$ & 1.364 & 11.8 & 0.893 & $1.40 \mathrm{E}+17$ \\
\hline 23 & 201809111907 & 42.821 & 141.996 & 33 & 4.2 & $1.48 \mathrm{E}+15$ & 3.214 & 11.2 & 9.096 & $6.04 \mathrm{E}+17$ \\
\hline 24 & 201809121824 & 42.676 & 141.986 & 33 & 4.5 & $3.67 \mathrm{E}+15$ & 1.682 & 16.3 & 3.233 & $4.10 E+17$ \\
\hline 25 & 201809130134 & 42.612 & 141.95 & 31 & 4.2 & $2.18 \mathrm{E}+15$ & 2.253 & 18.3 & 4.615 & $4.37 \mathrm{E}+17$ \\
\hline 26 & 201809131506 & 42.698 & 141.986 & 34 & 3.9 & $6.03 E+14$ & 5.960 & 6.9 & 23.630 & $8.46 \mathrm{E}+17$ \\
\hline 27 & 201809140654 & 42.677 & 141.952 & 26 & 4.6 & $7.00 \mathrm{E}+15$ & 1.596 & 11.6 & 5.268 & $7.04 \mathrm{E}+17$ \\
\hline 28 & 201809140948 & 42.804 & 141.988 & 36 & 4.3 & $2.04 \mathrm{E}+15$ & 2.507 & 14.3 & 5.951 & $5.06 \mathrm{E}+17$ \\
\hline 29 & 201809141731 & 42.611 & 141.973 & 39 & 4.0 & $1.76 \mathrm{E}+15$ & 2.513 & 21.5 & 5.171 & $4.39 E+17$ \\
\hline 30 & 201809170251 & 42.718 & 141.863 & 27 & 4.6 & $7.43 E+15$ & 1.739 & 13.2 & 7.234 & $8.87 \mathrm{E}+17$ \\
\hline \multicolumn{11}{|c|}{ Mainshock of 4 other events (for comparison) } \\
\hline 1 & 199501170546 & 34.598 & 135.035 & 16 & 7.3 & $2.43 E+19$ & 0.111 & 10.7 & 6.152 & $1.18 \mathrm{E}+19$ \\
\hline 2 & 200412141456 & 44.074 & 141.703 & 9 & 6.1 & $4.44 \mathrm{E}+17$ & 0.339 & 7.8 & 3.202 & $2.01 \mathrm{E}+18$ \\
\hline 3 & 201604142126 & 32.742 & 130.809 & 11 & 6.5 & $1.74 \mathrm{E}+18$ & 0.206 & 20.7 & 2.816 & $2.92 \mathrm{E}+18$ \\
\hline 4 & 201604160125 & 32.755 & 130.763 & 12 & 7.3 & $4.42 E+19$ & 0.069 & 19.2 & 2.688 & $8.31 E+18$ \\
\hline
\end{tabular}

$$
M_{i}^{(m)}=\frac{M_{0}}{\left[1+\left(f / f_{c}\right)^{2}\right]\left[1+\left(f / f_{\max }\right)^{2}\right]}
$$

Here, $M_{i}$ is source spectral density function $\left(10^{4} \mathrm{~N} \cdot \mathrm{m}\right)$, $V_{S}$ is shear wave velocity $(\mathrm{m} / \mathrm{s}), \rho$ is density $\left(10^{-3} \mathrm{~kg} / \mathrm{m}^{3}\right)$, $R_{\theta \emptyset}$ is average coefficient of Radiation pattern (0.55), $F_{S}$ is free surface effect and $P_{\mathrm{R}}$ is energy partition ratio $(1 / \sqrt{ } 2)$.

For comparison, Table 1 also shows the same information for the 1995 Hyogo-ken Nanbu earthquake, the earthquake of December 14, 2004, in the southern Rumoi district in Hokkaido, and the foreshock and the mainshock of the 2016 Kumamoto earthquake.

Although we omitted a figure due to the space limitation, we compared the site amplifications before and after including new data of the 2018 Hokkaido IburiTobu earthquake and confirmed that the difference was not significant. 


\section{Estimation of short-period level and stress drop}

The stress drop was evaluated using Eq. (5) based on the relational expression proposed by Brune (1970) with the formula of Eshelby (1957). The short-period level $A$ was evaluated using Eq. (6). It should be noted that these equations were derived from the assumption that the source of an earthquake is a single circular crack and that the seismic energy is radiated from the entire fault.

$$
\begin{aligned}
& \Delta \sigma=7 / 16 \cdot M_{0} \cdot\left(f_{c} /\left(0.37 \cdot V_{S}\right)\right)^{3} \\
& A=4 \pi^{2} \cdot f_{c}^{2} \cdot M_{0}
\end{aligned}
$$

Here $\Delta \sigma$ is Brune's stress drop, $M_{0}$ is the seismic moment and $V_{\mathrm{S}}$ is the shear wave velocity of the source fault area. In addition, $V_{\mathrm{S}}$ was set at $3600 \mathrm{~m} / \mathrm{s}$ for crustal earthquakes.

Figure 2 summarizes the stress drop and the shortperiod level $A$, which were evaluated using the corner frequency $f_{\mathrm{c}}$ from GIT. Figure 2a shows the relationship between the $M_{0}$ and $f_{\mathrm{c}}$. Figure $2 \mathrm{~b}$ shows the relationship between the $M_{0}$ and the stress drops. Figure 2c shows the relationship between the $M_{0}$ and $A$. Figure 2d shows the relationship between the focal depth and the stress drop. In these figures, the black open circle indicates the values of all the other crustal earthquakes used in GIT, the yellow star indicates that of the mainshock of the 2018 Hokkaido Iburi-Tobu earthquake, and the red circles indicate those of the aftershocks of the 2018 Hokkaido Iburi-Tobu earthquake.

Figure 2a also shows the regression equation for all the data of seismic moment $M_{0}$ and corner frequency $f_{\mathrm{c}}$. As shown in this figure, the $f_{\mathrm{c}}$ shows a strong positive correlation to the $M_{0}$. The relationship between the $M_{0}$ and $f_{\mathrm{c}}$ tends to be different from each other for earthquakes with the $M_{0} \geq 1.0 \times 10^{18} \mathrm{~N} \cdot \mathrm{m}$. This tendency is reflected to the same moment dependency observed in Figs. 2b, c.

In Fig. 2b, the stress drops of the 2018 Hokkaido Iburi-Tobu earthquake (mainshock) were approximately $10 \mathrm{MPa}$. This value almost corresponds to the upper limit of the stress drops of crustal earthquakes evaluated in the present study. The stress drops of the aftershocks of this earthquake were generally either the same as or smaller than that of the mainshock. A similar tendency was pointed out by Somei et al. (2014).

In Fig. 2c, the short-period level $A$ for the mainshock of the 2018 Hokkaido Iburi-Tobu earthquake is higher than other events with the same $M_{0}$. The $A$ of the aftershocks of the 2018 Hokkaido Iburi-Tobu earthquake is equal to or lower than that of the mainshock. Figure $2 \mathrm{c}$ also shows empirical formulae proposed by Satoh (2011). The $A$ of the 2018 Hokkaido Iburi-Tobu earthquake (mainshock) was slightly lower than that of the empirical formula (reverse fault earthquake) proposed by Satoh (2011). Equation (7) is a regression line evaluated by using all data classified Type $C$ in this study, and Eq. (8) is the line estimated by using the data having $M_{0}$ over $10^{18} \mathrm{~N} \cdot \mathrm{m}$.

$$
\begin{aligned}
& A=1.3515 \times 10^{12} \times M_{0}^{1 / 3} \\
& A=2.2401 \times 10^{12} \times M_{0}^{1 / 3}
\end{aligned}
$$

Here, $A$ is the short-period level and $M_{0}$ is the seismic moment $(\mathrm{N} \cdot \mathrm{m})$. In Fig. 2c, these lines are relatively lower than the other empirical formula proposed by Satoh (2011). Basically, it is reasonable to expect that the value of the level $A$ estimated by GIT is the global value as the all energy radiated from point source, not specialized to asperities as the dynamic characteristics. As the condition of GIT analysis, Satoh (2011) used data within a hypocentral distance of $60 \mathrm{~km}$, while we used data within a hypocentral distance of $200 \mathrm{~km}$. Therefore, one of the reasons for this difference may come from the difference in attenuation characteristics.

As shown in Fig. 2d, the stress drops tend to increase with the focal depth. Although the range of deviation is relatively large, the stress drop has a positive correlation to the focal depth. The aftershock region of the 2018 Hokkaido Iburi-Tobu earthquake was extended from 25 to $40 \mathrm{~km}$, which is exceptionally deep for crustal earthquakes in Japan. Nakano et al. (2015) confirmed that the stress drops of crustal earthquakes and those of subduction zone earthquakes were connected at the boundary of $30 \mathrm{~km}$ in depth and that they share the same trend of the stress drops that increase with the focal depth. Therefore, if the earthquake location is correct as currently published by the JMA, the events during the 2018 Hokkaido Iburi-Tobu earthquake sequence are higher-stress events simply because they have occurred in a relatively higher confined stress state.

In Fig. 2e, we show the comparison of source spectra estimated by GIT and fitting spectra based on $\omega^{-2}$ model. We can see that the fitted spectra show good agreement with separated spectra by GIT, except for the mainshock in the lower end of frequency.

\section{Amplifications at sites in the near field}

Figure 3a shows amplification factors at sites inside Yufutsu Plain, as evaluated by GIT from weak motions with $P G A \leq 200 \mathrm{~cm} / \mathrm{s}^{2}$. In each graph, the solid red line indicates the mean value of the site amplification with full waves (i.e., for the whole observed duration), the dotted red line indicates the mean value $\pm \sigma$ of the site amplification with full waves calculated from site amplifications of individual records shown in gray lines, and 


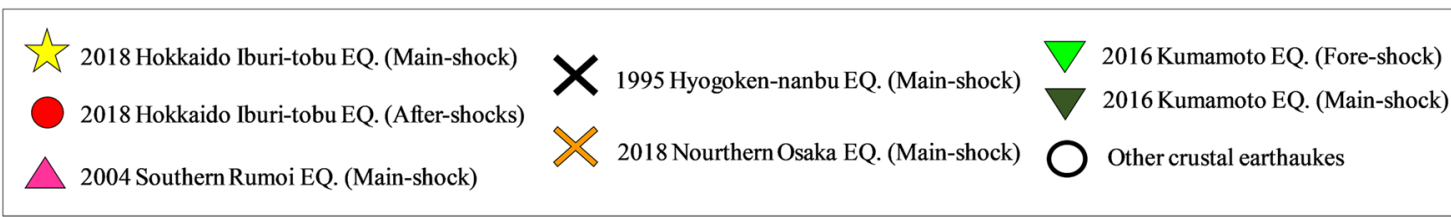

a
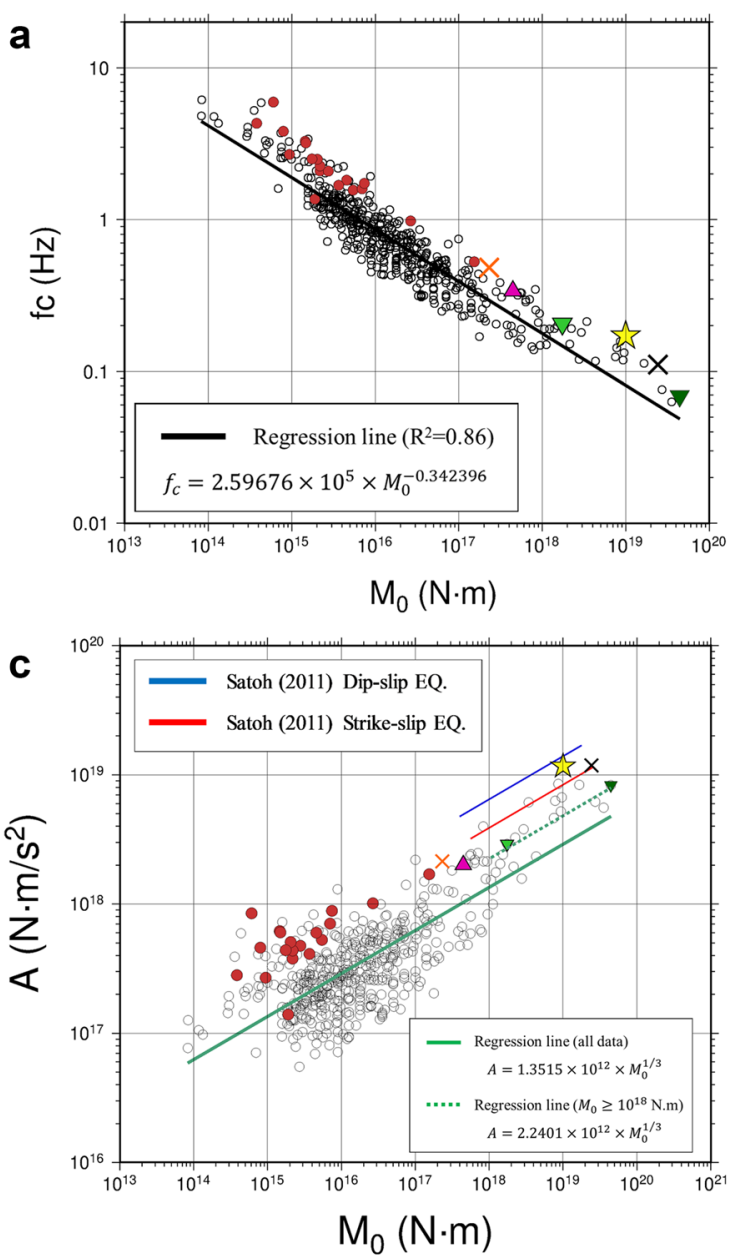

e

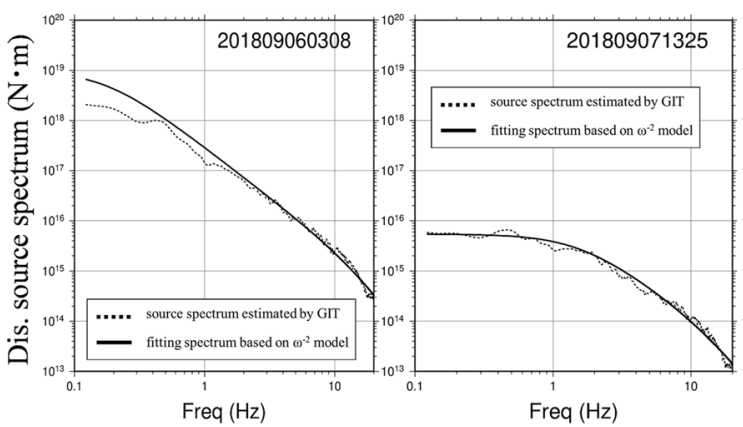

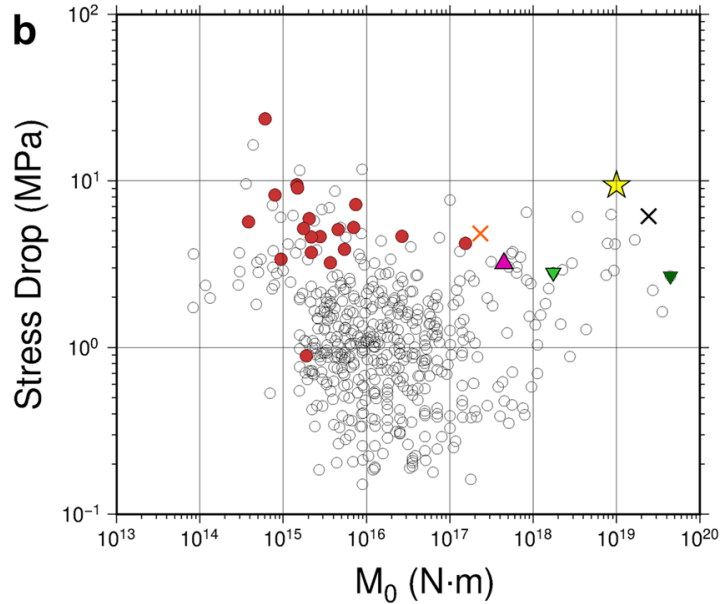

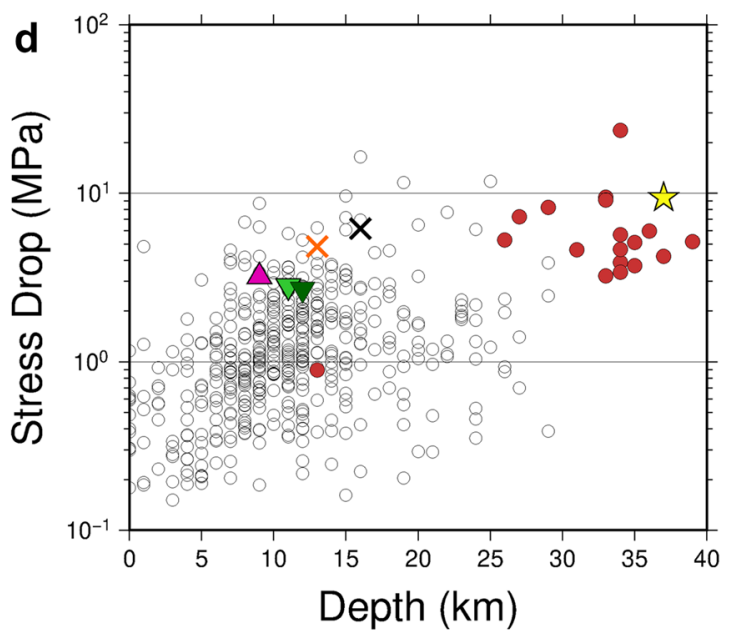

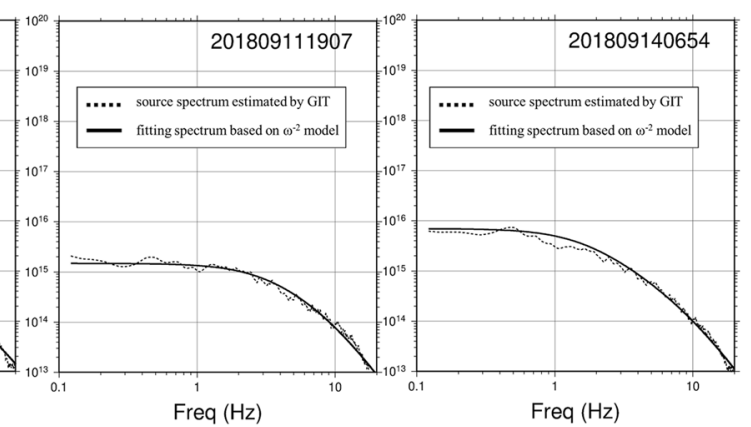

Fig. 2 a Comparison of $M_{0}$ and $f_{c}$ with the regression line. The regression coefficient is $R^{2}=0.86$, and so, the correlation is quite high. $\mathbf{b}$ Stress drops calculated by $f_{c}, M_{0}$ and $V_{S}$ at the source layer, as the Brun's stress parameter. $\mathbf{c}$ Level $A$ plot together with empirical formula proposed by Satoh (2011). We also show the regression line for the level $A$ of this study. Our regression lines are relatively lower than the others. $\mathbf{d}$ Comparison of stress drops and focal depth. It is clearly shown the dependency on the focal depth 
a
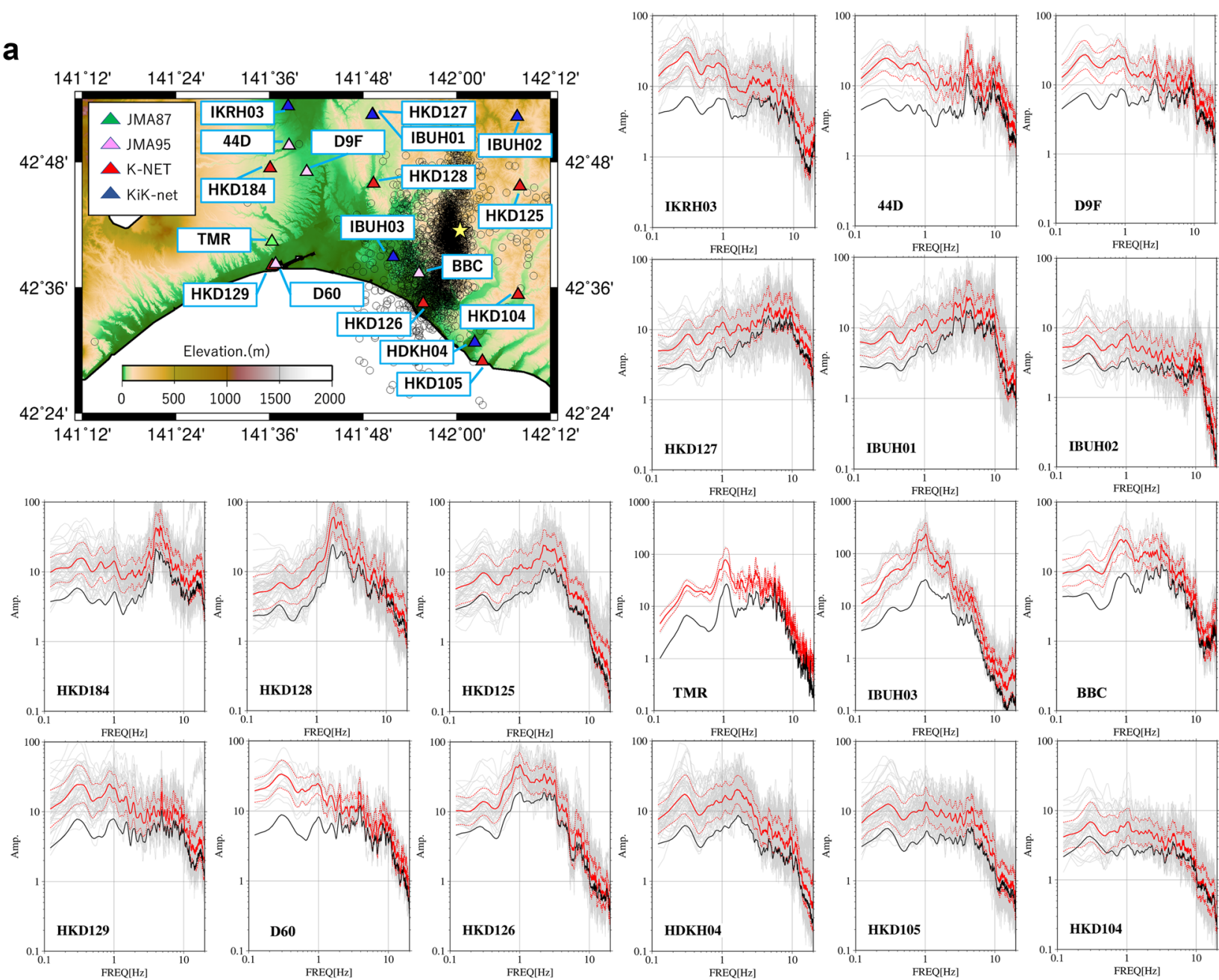

b

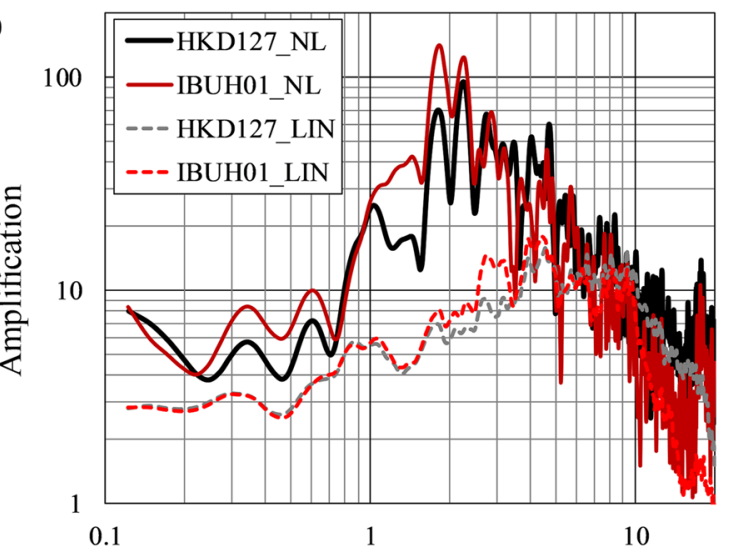

Freq. (Hz)

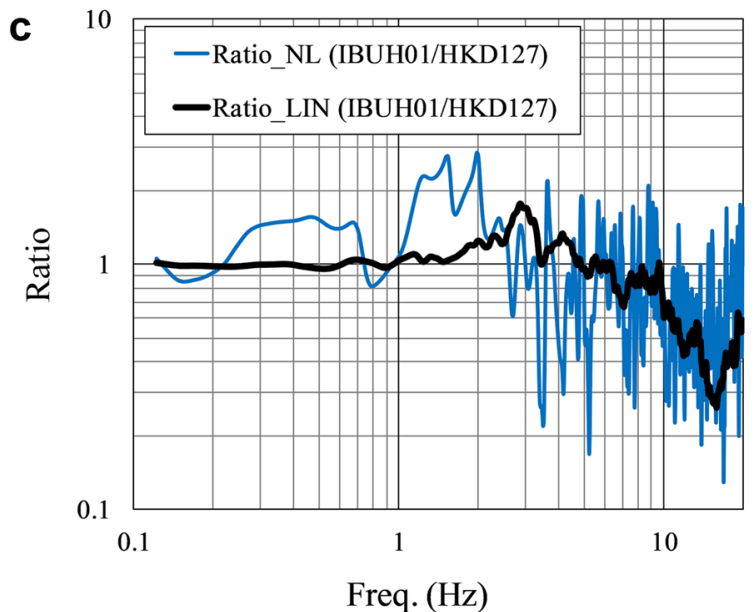

Fig. 3 a Comparison of site amplifications with S-wave and full-wave at Yufutsu Plain. b Site amplifications directly estimated by GIT and calculated at the mainshock of 2018 Hokkaido Iburi-Tobu earthquake, focusing on HKD127 and HKDH01. c Ratio of site amplifications with HKD127 and IBUHO1 
the solid black line indicates the site amplification with $\mathrm{S}$-waves (i.e., for only S-wave portion). The map at the upper left corner shows the sites evaluated in the present study and the earthquake location. As shown in this figure, at those sites inside Yufutsu Plain (i.e., IKRH03, 44D, D9F, HKD129, D60, BBC, HKD126 and IBUH03), the difference between the site amplification with full waves and that with $\mathrm{S}$-waves was large, especially in the frequency range lower than 1 or $2 \mathrm{~Hz}$, where the amplification factors with full waves are much higher than those with S-waves. Among them, three sites (BBC, HKD126 and IBUH03), where clear pulse-like waveforms were observed during the mainshock (Fig. 1b), showed dominant frequencies at approximately $1 \mathrm{~Hz}$, and their amplification factors were quite large. As discussed later, these amplification factors at lower frequencies are considered to be greatly affected by the deep underground structures below Yufutsu Plain. On the other hand, sites with altitudes relatively high (i.e., HKD127, HKD128, IBUH01 and HKD184) showed dominant frequencies above several $\mathrm{Hz}$.

We adopted the upper limit of PGA to be $200 \mathrm{~cm} / \mathrm{s}^{2}$ for GIT in this study. It is based on previous studies (e.g., Satoh 2011, Nakano et al. 2015). Wu et al. (2010) reported that the dominant frequency of the spectral ratio (surface to borehole) starts to deviate from the linear one even for the records with PGA $100 \mathrm{~cm} / \mathrm{s}^{2}$ or less at several sites in KiK-net. However, the site amplifications in this study are estimated as the average amplification from the seismic bedrock to the surface, and so, we think that they are not so strongly affected by the soil non-linearity, compared to the spectral ratios (surface to borehole) sensitive to the soil non-linearity within shallow layers. Furthermore, the number of waveforms with PGA from $50 \mathrm{~cm} / \mathrm{s}^{2}$ to $200 \mathrm{~cm} / \mathrm{s}^{2}$ is less than $6 \%$ of the total number of waveforms used for GIT. Therefore, we think that even if small non-linearity occurs at some sites with PGA higher than $50 \mathrm{~cm} / \mathrm{s}^{2}$, the impact on the source and site term evaluation is relatively small.

We then show comparisons of the site amplifications with S-wave at HKD127 and IBUH01 in Fig. 3b, c. Incidentally, HKD127 and IBU01 are installed in same area, and these stations are close to each other. In this paper, we calculated the site amplification "NL" by dividing the Fourier spectra observed during the mainshock with the product of the source terms and the pass term which are evaluated by GIT. On the other hand, the site amplifications estimated by GIT directly from weak motions are indicated by "LIN." In Fig. 3b, we showed the site amplifications indicated by "NL" during the mainshock of 2018 Hokkaido Iburi-Tobu earthquake in comparison with those of "LIN," and in Fig. 3c, we showed the ratio of the site amplifications between these two sites. Although these sites are located close to each other, the site amplification "NL" is significantly different, while the site amplification "LIN" is quite similar, in the range less than $10 \mathrm{~Hz}$. The ratio of "NL" between these two sites in the frequency range between 1 to $2 \mathrm{~Hz}$ is 2 to 3 times larger than that of "LIN."

As seen in these two sites, there are sites that show the peak frequency shift during the mainshock of the 2018 Hokkaido Iburi-Tobu earthquake, compared to the site amplifications estimated by GIT. We think that it is caused by not only the nonlinear site responses but also the effects of pass and source, because the site amplification "NL" reflects the overall differences between the behaviors in strong motions with large amplitude and the factors of source, pass and site amplifications estimated by GIT as linear characteristics "LIN." In particular, we think that the source term (forward rupture directivity mentioned above) affected strongly to the sites (BBC, HKD126 and IBUH03) where the pulse-like waveforms with the predominant frequencies lower than $1 \mathrm{~Hz}$ are observed (Fig. 1b). It is quite interesting so that we will conduct further investigation about its cause.

\section{Deep underground structure in eastern lburi region}

We investigated the effects of the deep ground structure at points near the epicenter using a deep underground model (JIVSM 2012) published by HERP (2012).

Figure 4a shows the observations and the locations of cross sections to investigate the effects of the underground structure. In this figure, the star indicates the location of the epicenter. The A-A' cross section is an east-west line, and the B-B' cross section is a line along N15 W-S15E.

Figure $4 \mathrm{~b}, \mathrm{c}$ shows the depths of upper seven layers on the A-A' and B-B' cross sections, respectively. As shown in these figures, the bedrock $\left(V_{\mathrm{S}} 2.9 \mathrm{~km} / \mathrm{s}\right)$ on the A- $A^{\prime}$ cross section becomes deeper at a point where the A-A' cross section intersects the B-B' cross section, and it becomes shallower at a point near the epicenter. The bedrock in the B-B' cross section becomes shallower as the distance from $B$ on the $B-B^{\prime}$ line becomes shorter, and it becomes deeper at a point where the B-B' cross section intersects the A-A' cross section. Regarding the B-B' cross section, the depths of the $V_{\mathrm{S}} 1 \mathrm{~km} / \mathrm{s}$ or $1.5 \mathrm{~km} / \mathrm{s}$ layers become deepest (around $600 \mathrm{~m}$ and $2000 \mathrm{~m}$, respectively) under IBUH03. This indication may be related to the fact that the ground amplification at IBUH03 is relatively large, as shown in Figs. 4d, e.

We would like to discuss site amplifications again. Six points shown in Fig. 4a are sites along the B-B' line. Among these sites, site amplification with $\mathrm{S}$-waves and site amplification with full waves are the largest at IBUH03, as shown in Figs. 4d, e. Site amplifications with 


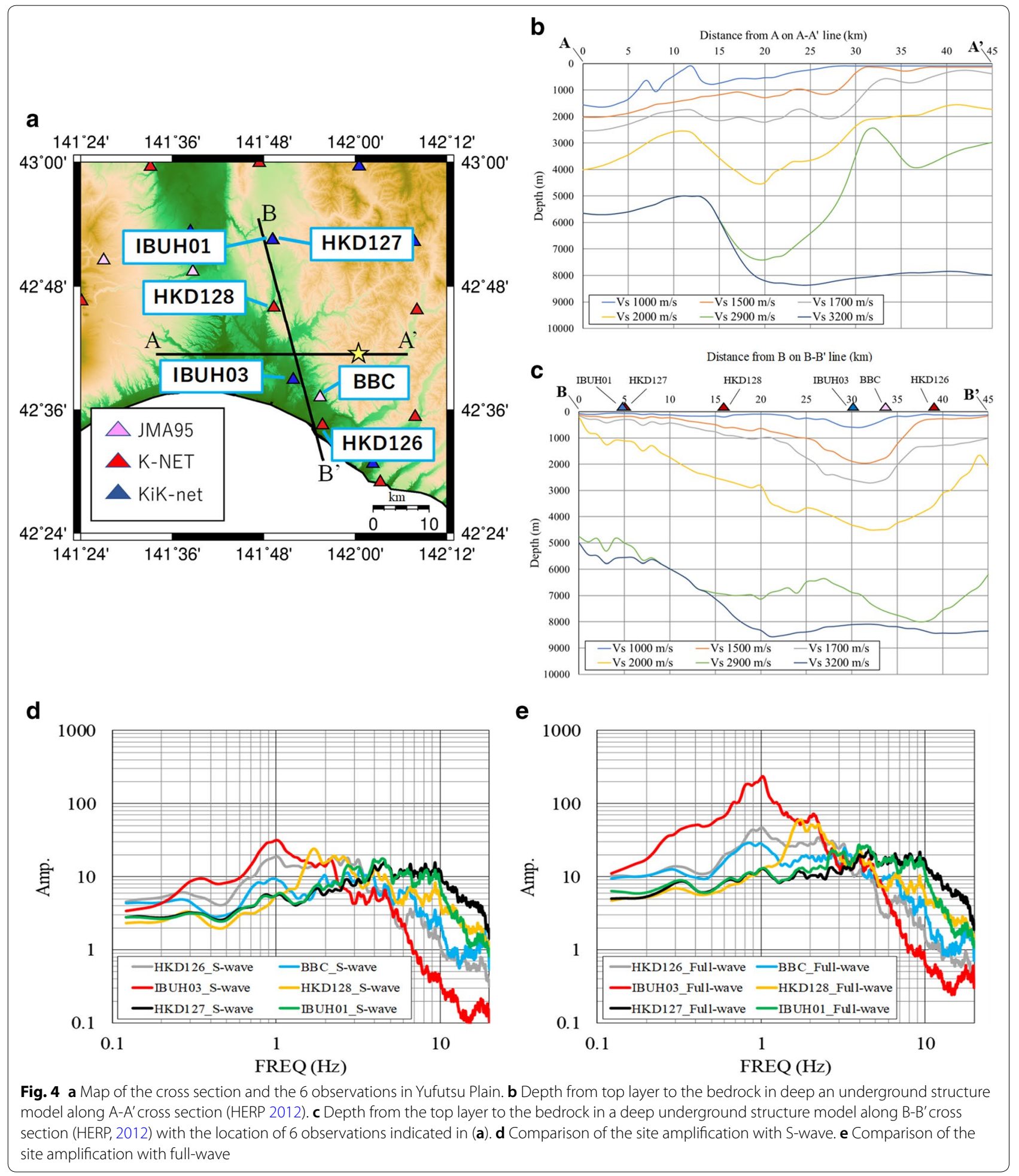

full waves are much larger than site amplifications with $\mathrm{S}$-waves when the dominant frequencies are 1 or $2 \mathrm{~Hz}$ as mentioned before. However, the site amplification with full waves is extraordinarily large at IBUH03.
When Figs. 4b, c are carefully reviewed, it can be confirmed that the bedrock right under IBUH03 sinks. IBUH03 is near a point where the A-A' cross section intersects the B-B' cross section. At the sunken place, the 
bedrock depth at $V_{\mathrm{S}} 2.9 \mathrm{~km} / \mathrm{s}$ or $V_{\mathrm{S}} 3.2 \mathrm{~km} / \mathrm{s}$, which corresponds to the seismological bedrock, is almost 6-7 km. When referring to geographical classification proposed by Wakamatsu and Matsuoka (2013), IBUH03 corresponds to back swamp, so IBUH03 is presumed to be affected by the amplification of the surface ground, too.

It is not totally clear at this moment the mechanism of strong motions observed in the Yufutsu Plain during the 2018 Hokkaido Iburi-Tobu earthquake. However, as a qualitative explanation, it could be said that the moderately long-period pulse-like waves, which were generated by directivity effects according to rupture propagation on the fault plane, grew up because of site amplifications based on the underground structure in the Yufutsu Plain, especially in the long-period range. In order to quantitatively reproduce the waveforms during mainshock and evaluate site amplifications, we have to perform further studies on the influence of the shallow subsurface structure as well as the deep underground structure.

\section{Conclusions}

The results obtained in the present study can be summarized as follows:

- We evaluated the source characteristics of the mainshock and aftershock of the 2018 Hokkaido IburiTobu earthquake using GIT. As a result, the stress drop of the mainshock was approximately $10 \mathrm{MPa}$, and that of the aftershock was distributed below $10 \mathrm{MPa}$. The short-period level $A$ was estimated to be $1.17 \times 10^{19} \mathrm{~N} \cdot \mathrm{m} / \mathrm{s}^{2}$.

- Together with the above-mentioned source characteristics, we evaluated the ground amplification characteristics on Yufutsu Plain using GIT. Sites in the southern part of Yufutsu Plain, including Atsuma Town, have dominant frequencies of approximately $1 \mathrm{~Hz}$. Sites in the northern part of Yufutsu Plain have dominant frequencies of several $\mathrm{Hz}$. This reflects the fact that the bedrock depth of the underground structure in this area becomes gradually deeper from north to south.

- When site amplification with S-wave was compared with site amplification with full waves, the difference between these two amplifications was small at sites with high altitudes with high peak frequencies, while the difference was large at sites with low altitudes with low peak frequencies. At KiK-net Atsuma (IBUH03), the site amplification with full waves was the largest.

- Using the deep underground model (JIVSM, 2012), two lines were drawn on Yufutsu Plain. As a result, we can see that the bedrock depth gradually deepened from north to south, while the center part of the east-west line was deepest, and that the bedrock depth was also deeper at a point where these two lines intersected. Because the deeper zone of bedrock depth with the hollow shape exists in a place surrounding IBUH03, the hollow might be related to waveforms of large amplitude observed in this area.

- Based on the findings obtained in the present study, we will examine factors for seismic damage using theoretical simulations of strong ground motions in Yufutsu Plain.

Thus, we can conclude that the 2018 Hokkaido IburiTobu earthquake showed again the importance of quantitative evaluation of the source and site effects to understand particular phenomena observed during a specific earthquake. We solved some of the questions raised, but we found others remained to be solved through further investigations.

\begin{abstract}
Abbreviations
CEORKA: Committee of Earthquake Observation and Research in the Kansai Area; GIT: generalized inversion technique; GSI: Geospatial Information Authority of Japan; HERP: Headquarters for Earthquake Research Promotion in Japan; JIVSM: Japan Integrated Velocity Structure Model; JMA: Japan Meteorological Agency; NIED: National Research Institute for Earth Science and Disaster Resilience in Japan; NILIM: National Institute for Land and Infrastructure Management; PGA: peak ground acceleration.
\end{abstract}

\section{Acknowledgements}

We use the waveforms published by JMA, CEORKA, K-NET, KiK-net. We illustrated the few graphs using GMT (Wessel and Smith 1998). We appreciate all persons concerned these projects.

\section{Authors' contributions}

KN wrote the initial draft of the manuscript through discussion with HK. Final manuscript is written by both authors based on the discussions for this manuscript. Both authors read and approved the final manuscript.

Funding

None.

\section{Availability of data and materials}

The waveforms used in this study are available from the following organizations: CEORKA, K-NET, KiK-net and JMA.

\section{Competing interests}

The authors declare that they have no competing interests.

\section{Author details}

${ }^{1}$ Technical Research Institute, HAZAMA ANDO CORPORATION, 515-1 Karima, Tsukuba 305-0822, Japan. ${ }^{2}$ Disaster Prevention Research Institute, Kyoto University, Gokasho, Uji, Kyoto 611-0011, Japan.

Received: 24 February 2019 Accepted: 4 June 2019

Published online: 13 June 2019

\section{References}

Brune JN (1970) Tectonic stress and spectra of seismic shear waves from earthquakes. J Geophys Res 75:4997-5009. https://doi.org/10.1029/JB075 i026p04997 
Eshelby JD (1957) The determination of the elastic field of an ellipsoidal inclusion, and related problems. Proc R Soc Lond Ser A 241:376-396

Fukuyama E, Ishida M, Dreger Douglas S, Kawai H (1998) Automated seismic moment tensor determination by using on-line broadband seismic waveforms. Zisin Series II(1):149-156 (in Japanese with English abstract)

Geospatial Information Authority of Japan (2018) A fault model estimated by diastrophism (Preliminary version), http://www.gsi.go.jp/cais/topic18091 2-index.html (in Japanese, accessed at 15 Jan 2019)

Headquarters for Earthquake Research Promotion (2012) Long-period ground motion prediction map, https://www.jishin.go.jp/evaluation/seism ic_hazard_map/lpshm/12_choshuki/ (accessed at 15 Jan 2019)

Nakano K, Kawase H, Matsushima S (2015) Statistical properties of strong ground motions from the generalized spectral inversion of data observed by K-NET, KiK-net, and the JMA shindokei network in Japan. Bull Seismol Soc Am 105(5):2662-2680. https://doi.org/10.1785/0120140349

Nakano K, Kawase H, Matsushima S (2019) A study on the site amplifications estimated by generalized inversion technique. J Jpn Assoc Earthq Eng (in Japanese with English abstract, in press)

National Institute for Land and Infrastructure Management (2018) Survey report on the foundation and ground damage of buildings due to the Hokkaido Eastern Earthquake, http://www.nilim.go.jp/lab/bbg/saigai/ (in Japanese, last accessed at 15 Jan 2019)
Satoh T (2011) Scaling of short-period spectral level of acceleration source spectra for aftershocks and foreshocks of the 2011 off the pacific coast of Tohoku earthquake. In: 4th IASPEI/IAEE international symposium on the effects of surface geology on seismic motion, 1.3

Somei K, Asano K, Iwata T, Miyakoshi K (2014) Source scaling of inland crustal earthquake sequences in Japan using the S-wave coda spectral ratio method. Pure appl Geophys 171(10):2747-2766. https://doi.org/10.1007/ s00024-014-0774-2

Wakamatsu K, Matsuoka M (2013) Nationwide 7.5-arc second Japan engineering geomorphologic classification map and Vs30 zoning. J Disaster Res 8(5):904-911. https://doi.org/10.20965/jdr.2013.p0904

Wessel P, Smith WHF (1998) New, improved version of the generic mapping tools released. EOS Trans AGU 79:579

Wu C, Peng Z, Ben-Zion Y (2010) Refined thresholds for non-linear ground motion and temporal changes of site response associated with mediumsize earthquakes. Geophys J Int 182:1567-1576. https://doi.org/10.1111/ j.1365-246X.2010.04704.x

\section{Publisher's Note}

Springer Nature remains neutral with regard to jurisdictional claims in published maps and institutional affiliations.

\section{Submit your manuscript to a SpringerOpen ${ }^{\circ}$ journal and benefit from:}

- Convenient online submission

- Rigorous peer review

- Open access: articles freely available online

- High visibility within the field

- Retaining the copyright to your article

Submit your next manuscript at $\boldsymbol{\nabla}$ springeropen.com 